\title{
RELIGIOSIDADE, TERRITORIALIDADE E PARTICIPAÇÃO POPULAR NO ESPAÇO URBANO.

\author{
Considerações sobre a influência do discurso religioso na participação \\ popular.
}

\section{RELIGIOSITY, TERRITORIALITY AND POPULAR PARTICIPATION IN URBAN SPACE. Considerations on the influence of religious discourse on popular participation.}

\author{
A. Raquel Gomes Valadares \\ IAU, Instituto de Arquitetura e Urbanismo; Universidade de São Paulo, Brasil \\ valadaresgr@gmail.com
}

\begin{abstract}
RESUMO
O objetivo desta análise é apresentar considerações sobre as influências das diferentes vertentes de interpretações do cristianismo nas periferias urbanas brasileira e como isso têm reverberado na consolidação da consciência política. Busca-se compreender o papel da Igreja como ator social na constituição da periferia urbana. As considerações apresentadas incidem sobre dois movimentos teológicos díspares: a Teologia da Libertação e a Teologia da Prosperidade. É possível inferir que a conduta religiosa reverbera na ação da população, difundindo valores no trabalho, na política e nas relações sociais. Na cidade há um processo contínuo da produção social do espaço que integra inúmeras dimensões; a territorialidade, as articulações políticas e as dinâmicas sociais são temáticas necessárias para compreendê-la. Nesta análise, procura-se pontuar como o discurso religioso influencia a participação política no espaço. Trata-se de produção históricodescritiva, utilizando o método revisão de literatura, que permite transitar pela compreensão histórica e o aprofundamento na problemática contemporânea.
\end{abstract}

Palavras-chave: Produção social do espaço, religiosidade, participação popular.

Sessão temática: 3. Dinâmica urbana.

Tema: Cidades pós-crise e dinâmicas socioespaciais

\section{ABSTRACT}

The objective of this analysis is to present considerations on the influences of the different strands of interpretations of Christianity in the Brazilian urban peripheries and how this has reverberated in the consolidation of political consciousness. It seeks to understand the role of the Church as an incident actor in the constitution of the urban periphery. The considerations presented focus on two disparate theological movements: Liberation Theology and Prosperity Theology. It is possible to infer that religious conduct reverberates in the action of the population in the city, defining values of work, politics and social relations. In the city there is a process of social production of the space that integrates many dimensions; the territoriality, 


\section{SÃO PAULO15 17 LISBOA $25 \sim 26$ JUN 2020}

the habitation and the social dynamics are necessary themes to understand it. In this analysis, we try to point out how religious discourse influences political participation in urban space. Thus, using the historicaldescriptive method, this analysis results in the understanding of academic productions on the theme.

Keywords: Social production of space, religiosity, popular participation.

Thematic clusters: 3 . Urban dynamics.

Theme: Post-crisis cities and socio-spatial dynamics

\section{Introdução}

A cidades são formadas num processo de produção social no espaço que integra inúmeras dimensões. Para a análise deste processo é necessária a devida acuidade considerando as distintas experiências, pois são possíveis variações de desenvolvimento e crescimento externa e internamente, ou seja, há variações dentro do mesmo território, de uma cidade para outra, e diferenças de infraestrutura e atendimento entre áreas da mesma cidade. Além disso, as particularidades históricas e identitárias precisam ser levadas em conta, a fim de que seja evitado o reducionismo demasiado e generalista da complexidade dos territórios.

Tomando o termo "produção" num sentido amplo (produção de obras e produção de relações sociais), houve na história uma produção de cidades assim como houve produção de conhecimentos, de cultura, de obras de arte e de civilização, assim como houve, bem entendido, produção de bens materiais e de objetos práticosensíveis. [...] A cidade foi e continua a ser objeto; mas não à maneira de um objeto manejável, instrumental [...] A cidade escrita e prescrita, isto quer dizer que ela significa: ela ordena, ela estipula. O quê? Cabe à reflexão descobrir (Lefebvre, 2001: 53-54)

Ao tratar da cidade é inequívoco não pensar na dimensão do lugar e a das relações sociais estabelecidas a partir da territorialidade. Segundo Cacciari (2010), o lugar é uma necessidade física a todas as formas de vida comunitária:

Ora bem, será possível viver sem um lugar? Será possível habitar onde não existem lugares? O habitar não tem lugar lá onde se dorme e, por vezes, se come, onde se vê televisão e se diverte com o computador de casa; o lugar do habitar não é o mero alojamento. Só uma cidade pode ser habitada; mas não é possível habitar a cidade se ela não se dispuser a ser habitada, ou seja, se não "der" lugares. O lugar é o sítio onde paramos: é a pausa - é análogo ao silêncio de uma partitura. (Cacciari, 2010: 35).

Tal qual descrito por Machado da Silva (2016), a Sociologia Urbana se preocupa com a territorialidade, a condição do habitar e o modo como a população está organizada no espaço físico. Os fluxos migratórios populacionais, a debilidade da provisão habitacional e as estratégias de participação popular são exemplos dos múltiplos eixos de pesquisas sociológicas envolvendo o âmbito urbano.

Ao tratar da participação popular, busca-se compreendê-la a partir dos princípios constitucionais; dentre eles, destacam-se os princípios da igualdade e da democracia. Tais princípios constam no preâmbulo constitucional (Brasil, 1988), inferindo que todas as demais normas infraconstitucionais devem obedecer a este ditame.

Segundo a categorização doutrinária, os direitos fundamentais são sistematizados em dimensões, ou seja, um conjunto de direitos gradualmente positivados e apropriados socialmente. Anteriormente, a doutrina jurídica 


\section{SÃO PAULO15 $\sim 17 \cdot$ LISBOA $25 \sim 26$ JUN 2020

denominava tais categorias como gerações; assim, incorria a denominação primeira, segunda e terceira geração, e assim por diante. No entanto, a preferência por esta nominação apresenta grave erro, uma vez que geração compreende na substituição de uma categoria por outra, e não na sua coexistência (Carneiro, 2019).

Deste modo, preferiu-se o uso do termo dimensões. A primeira dimensão de direitos concerne à liberdade individual (de pensamento, expressão, religiosa, entre outras) e aos direitos políticos (Lenza, 2013; Carneiro, 2019). A segunda dimensão de direitos, de acordo com Lenza (2013) trata sobre a igualdade, amparando os direitos sociais, econômicos e culturais. Um preceito complexo e caro à sociedade (Bobbio, 2004).

Canotilho (2003) questiona sobre a igualdade postulada pela norma:

Ser igual perante a lei não significa apenas a aplicação igual da lei. A lei, ela própria, deve tratar por igual todos os cidadãos. O princípio da igualdade dirige-se ao próprio legislador, vinculando-o à criação de um direito igual para todos os cidadãos. Mas o que significa "criação de direito igual?" (Canotilho, 2003: 426).

Segundo o referido autor, caberia ao Estado promover mecanismos de alcance da igualdade, por meio do seu poder diferenciado e suas competências. A alteração dos mecanismos e estruturas, consequentemente, resultaria na igualdade e no acesso democrático, ao menos no patamar mínimo, que assegure a todos os direitos fundamentais, um mínimo existencial. A proposta de uma sociedade cuja igualdade seja verificável e aplicada com justiça, segundo Canotilho, "designa uma relação entre diversas pessoas e coisas" (2003, p.428).

Nas lições de Bobbio (2004), a terceira dimensão de direitos é heterogênea e imprecisa, vez que, busca tutelar direitos fraternos ou da coletividade. Dentre os direitos reivindicados, o direito ao ambiente não poluído é o mais importante deles (Bobbio, 2004).

A quarta dimensão de direitos atingiria a cidadania (Bobbio, 2004). Este quarto âmbito de direitos é um dos mais amplos e permeáveis às demais dimensões. Além disso, na concepção de Lenza (2013), na quarta dimensão de direitos caberia também a tutela da democracia direta, à informação e ao pluralismo. A quinta dimensão, para Carneiro (2019), invoca o direito à paz e a sexta dimensão o direito à água potável.

Os direitos fundamentais possuem características imanentes e relevantes. Eles são históricos, uma vez que resultam de uma construção social ao longo do tempo e não estão baseados no direito natural (Silva, 2005). São intransferíveis, irrenunciáveis e inalienáveis (Silva, 2005). Portanto, conforme assevera o texto constitucional, o poder emana do povo, isto é, uma construção social, irrenunciável, intransferível e inalienável. Embora seja irrenunciável, as concepções do princípio democrático asseguram que o poder de constituir normas pertence ao povo, que de forma direta ou representativa expressam seus anseios.

Ao referir-se a povo, a construção linguística, nem sempre estava se referindo ao mesmo grupo. De acordo com Chartier (2002), a mesma palavra poderia designar dois grupos distintos no latim: populus e plebs. O povopopulus designa todo e qualquer habitante, o povo-plebs define aquele que não pode ser considerado sujeito político, indivíduo não dotado de direitos. Desse modo, ao rigor da palavra, o que era referido como público poderia não ser tangível a todo o povo; emergindo um espaço próprio da política esvaziado do popular.

Canotilho (2003) afirma que povo não é uma classe socioeconômica, mas compreende um grupo de pessoas que manifestam ideias, interesses e representações políticas; está além de uma formação momentânea. $\mathrm{Na}$ compreensão doutrinária do direito, o povo a quem se refere a Constituição é o populus; entretanto, na prática, o que se vê é a limitação do aspecto participativo e a redução do significado popular e a exclusão da plebs. 


\section{SÃO PAULO15 $\sim 17 \cdot$ LISBOA $25 \sim 26$ JUN 2020

A democracia participativa possibilita que os cidadãos sejam representados por seus eleitos, bem como sejam consultados sobre as decisões do poder legislativo; é possível o controle popular através do referendo, plebiscito, iniciativa popular e ação popular. A população pode se agregar em torno de diversos valores políticos e até mesmo o fato de buscar a neutralidade ou indiferença na participação política insurge uma forma de atuação política.

A proposta apresentada nesta análise é identificar elementos que interseccionam a participação popular, a territorialidade e as práticas do discurso religioso, compreendendo a confluência desses elementos não como determinismo sociológico, mas como uma convergência, um emaranhado de descontinuidades sobrepostas. A religião se ancora nas experiências do cotidiano; ela não se limita a estabelecer a conexão do sujeito ao ser divino, mas espraia pelas dimensões da vida, tornando-se fundante em todo o código de pensamento e conduta.

\section{Territórios periféricos e a política urbana}

Compreendendo que esta análise incorre sobre a produção social do espaço e nuanças das relações sociais dos habitantes, é incontestável abordar sobre a segmentação espacial em decorrência dos rendimentos econômicos. O espaço urbano reflete a condição desigual da vida em sociedade; a concentração da pobreza revela-se no surgimento e expansão dos bairros periféricos, sem infraestrutura adequada, influindo na baixa qualidade de vida.

Tratando da ocupação do espaço urbano, Telles (1993) destaca que na sociedade brasileira há uma profunda contradição, uma vez que se verifica o desenvolvimento industrial, o crescimento urbano e a modernização institucional, no entanto, a pobreza não foi superada. Pelo contrário, a pobreza transbordou os contornos de definição outrora antepostos na composição das franjas do mercado de trabalho, no submundo do mercado informal, nos confins das áreas rurais e do nordeste hierárquico, atingindo também os trabalhadores urbanos, integrados aos centros econômicos mais dinâmicos.

Essas contradições possuem relações com as crises econômicas, que produzem efeitos que reverberam em distintas escalas, com a precariedade dos serviços públicos e, além disso, com a formulação de programas de governo que mantém a tradição conservadora e autoritária, perpetuando os mesmos entraves para a superação da pobreza. Para Teles (1993), a pobreza sempre foi objeto do discurso político, porém a justiça social e a igualdade nunca estiveram nas pautas dos discursos, tampouco da vontade política.

Vê-se, assim, a pobreza como efeito indesejado, sem autores ou responsáveis indicados, exposta como resíduo que escapou à potência civilizadora da modernização, fixando no futuro a capacidade de redenção ainda não alcançada. A pobreza implica em marca e fixação da inferioridade e na inacessibilidade de direitos sociais. Na análise de Teles (1993), um exemplo pragmático dessas relações hierarquizadas são as relações de trabalho. O trabalho formal regulamentado pelo Estado estabelece um modelo de cidadania e proteção social. Nessas relações, há um escalonamento do acesso aos direitos, pois considera que nem todos são iguais perante a lei e que os direitos são para aqueles que mantém a respeitabilidade.

Desse modo, Teles (1993) chama a atenção para a formulação da concepção de cidadania desatrelada dos direitos civis-políticos e o acesso aos direitos sociais como recompensa do cumprimento do dever do trabalho. Mesmo com as lutas sindicais, reinvindicações e conquistas trabalhistas, essa tradição na perspectiva de acesso a direitos não foi superada; não foi possível democratizar o espaço fabril, o que incorre na pauperização da parcela majoritária dos trabalhadores, na instabilidade e despreparo destes. 


\section{SÃO PAULO15 $\sim 17 \cdot$ LISBOA $25 \sim 26$ JUN 2020

A estrutura social descrita em Teles (1993) tem a carteira de trabalho como um rito simbólico de formação da identidade social, reforçando a compreensão de que os direitos sociais só poderiam ser acessados por meio da obtenção desta identidade. Outro aspecto suscitado é a organização familiar; torna-se imperativo estar inserido em um núcleo familiar que garanta a estabilidade e sobrevivência dos seus membros.

O acesso aos direitos sociais estaria centrado nesse binômio, trabalho-família, cuja integração é perversa, pois alheio às relações formais de trabalho não há possibilidade de obtenção de cidadania e a inexistência de núcleo familiar, que garanta dignidade e moralidade, também influirá nas regras culturais que organizam os modos de vida.

O preço do crescimento econômico e progresso industrial sobrecarregou o trabalhador, e o mercado imobiliário passou a regular as questões referentes à moradia. A população pobre, que não consegue obter unidade habitacional nos valores de mercado, passou a ocupar áreas cada vez mais distantes do espaço de produção e afastadas, também, do acesso aos serviços e infraestrutura urbana. Na lógica do mercado imobiliário, identificada por Kowarick (1979), a classe média obtém a unidade habitacional financiada por meio dos créditos bancários, enquanto a classe trabalhadora fixa-se nas áreas periféricas com unidades habitacionais construídas por eles mesmos, com a ajuda de vizinhos e amigos.

A moradia foi inserida no texto constitucional, mediante emenda, assegurando a universalidade do direito; a garantia constitucional do direito à moradia é o aspecto formal da norma, enquanto que os programas e políticas públicas de organização do território e, consequentemente, o desenvolvimento de planos habitacionais tratam-se do aspecto material, ou seja, a materialização da lei. Entretanto, há um comportamento jurídico no Brasil de que algumas normas são cumpridas em detrimento de outras, que se limitam a mera letra da lei (Ribeiro e Cardoso, 2012). A previsibilidade, o ato de estar previsto em lei, nem sempre se constitui a concretude do direito.

Segundo Carrión (1991: 115), "la ausencia de política urbana se ha convertido en la política urbana, porque se carece de propuestas urbanas alternativas". E tal assertiva se aplica no território brasileiro; a ausência ou ineficiência das políticas urbanas transformou-se na política urbana vigente. Isto implica na difusão da gestão da cidade mediante os interesses de mercado e oferta de serviços públicos segundo a orientação do capital, sendo rentáveis a sobreacumulação:

A difusão na sociedade dos valores igualitaristas e de uma cultura do medo vem servindo de justificativa para um comportamento de secessão urbana, bloqueando fortemente a construção de uma relação de alteridade entre ela e as camadas populares, sem o que é impossível a construção de um projeto de futuro para as nossas cidades (Ribeiro e Cardoso, 2012: 24)

O mercado de moradia formal segrega em razão dos rendimentos, pois as cidades também estão estruturadas com base no capital. Privilegiaram-se os espaços de produção, em detrimento dos lugares de reprodução da vida. A parcela da população que possui menor rendimento tem se restringido a ocupar lugares cujo valor da terra é ínfimo. Neste raciocínio mercadológico, esta população é "empurrada" para os espaços mais longínquos.

Para Arretche (2014) a perspectiva da desigualdade social não se restringe apenas a uma análise dos rendimentos financeiros, mas ao acesso dos serviços públicos e da infraestrutura urbana. A dimensão do bemestar social deveria permitir um mínimo de condições de dignidade de cidadania. Desse modo, a inacessibilidade de serviços, ineficiência de infraestrutura ou equipamentos oferecidos a uma distância 


\section{SÃO PAULO15 $\sim 17 \cdot$ LISBOA $25 \sim 26$ JUN 2020

inconcebível à população, como energia elétrica, água potável, esgoto, coleta de lixo, transporte, atendimento em saúde e educação, é também a negação a cidadania para população que se instala ou é instalada nessas localidades.

Nesta disputa por lugares e possibilidades de habitabilidade existem tentativas de soluções coletivas, a perspectiva de ativação da participação popular e novas formas de definição de políticas públicas. Movimentos sociais de moradia urbana mobilizam a população periférica nesse sentido, buscando transformação social a partir da agregação coletiva. Gradativamente, torna-se clarividente que a cidade é o espaço do capital e, com isso, não há espaços equitativos. Há uma parcela que se serve dos direitos e garantias sociais, em detrimento de uma maioria que até mesmo as formas de articulações têm sido cerceadas ou desestimuladas.

\subsection{Exercício da religiosidade e suas influências no espaço urbano}

O período antecedente à Constituição de 1988 foi um momento difícil e conturbado da história nacional; no tocante à participação popular, verificou-se uma interessante experiência, a partir dos anos 1960, com as Comunidades Eclesiais de Base (CEBs). A CEB foi um movimento social nascido na Igreja Católica, com a finalidade de alcançar as pequenas comunidades; um movimento lastreado no discurso da Teologia da Libertação, que se tratava "da tentativa e do engajamento de parte dos setores eclesiais para territorializar a Igreja, dando uma feição mais real e objetiva à missão dessa instituição no mundo" (Mitidiero Junior, 2008: 4).

As comunidades eclesiais de base (CEB's) são pequenos grupos organizados em torno da paróquia (urbana) ou da capela (rural), por iniciativa de leigos, padres ou bispos. As primeiras surgiram por volta de 1960, em Nísia Floresta, arquidiocese de Natal, segundo alguns pesquisadores, ou em Volta Redonda, segundo outros. De natureza religiosa e caráter pastoral, as CEB's podem ter dez, vinte ou cinquenta membros. (Betto, 1985: 7).

As insatisfações e inquietudes debatidas em comunidade, em um espaço contínuo de encontros, buscavam formar a consciência de cidadania atrelada ao exercício de fé; nas décadas de 1960 até 1980, a desigualdade social no Brasil, bem como em toda a América Latina, encontrava os seus índices mais exacerbados, e a Igreja Católica tornou-se o espaço para discutir maneiras de minimizá-la. Um processo de discussões que culminariam em medidas de transformações na dimensão local, pois as questões suscitadas envolviam o cotidiano, com assuntos comuns, que versavam sobre o saneamento básico, a moradia, a educação básica e segurança pública.

As CEBs surgiram no período de enrijecimento da liberdade política e do governo militar autoritário, situação que limitava a participação popular e o debate político amplo. As reuniões tornaram-se também locais de discussão sobre reabertura política, direitos trabalhistas e, até mesmo, preservação da vida dos presos políticos.

Cidadãos se organizavam de forma coletiva para reivindicar mais liberdade, o retorno dos direitos políticos ou por questões mais locais como saneamento básico, moradia, segurança, entre outros. Deve-se destacar para isso o trabalho da Igreja na criação das CEBs (Comunidades Eclesiais de Base), e também dos fóruns, plenárias e reuniões sustentados por associações de bairro, entidades de classe e movimentos sociais. Somando a isso, não se deve esquecer que houve também um relaxamento gradual do aparelho repressivo do regime militar (Lin, 2010: 48-49). 


\section{SÃOPAULO15 17 LISBOA $25 \sim 26$ JUN 2020

Desta prática, leigos eram inseridos na participação das atividades da Igreja, emergindo líderes locais com voz ativa. A CEB foi um movimento social nascido na Igreja Católica, com a finalidade de alcançar os grupos minoritários, não representados na macropolítica ou comunidades periféricas. Tratou-se da interpretação mais marxista da religião cristã católica, em que os fiéis eram estimulados a debater demandas sociais no mesmo espaço de exercício da fé.

É importante comentar que a aproximação da Igreja Libertadora com o socialismo foi carregada de ambiguidades e contradições. Alguns teólogos aceitavam integralmente o conteúdo programático do partido comunista e da luta revolucionária, enquanto outros tinham posições mais brandas, expurgando qualquer possibilidade de violência na luta libertadora, dando ênfase ao processo de desenvolvimento pleno da humanidade e à ideia de uma revolução pacifista (Mitidiero Junior, 2008: 12).

Embora vinculada à religião, havia uma linha tênue ou quase imperceptível quanto à ação política e muitos dos líderes passaram a exercer cargos políticos em suas comunidades, ou até mesmo cooptados por partidos políticos. As comunidades de base, rurais e urbanas, estavam mais próximas das questões sociais e, ao final dos anos 1990, não foi possível identificar o mesmo engajamento de outrora. Incontestavelmente, as CEBs estimulavam o surgimento de lideranças locais, que tratavam do dia a dia em comunidade e próximos dos desníveis socioeconômicos. Entretanto, as tendências eclesiásticas majoritárias promoveram o afastamento dos temas sociais mais latentes, e diante do não fazer das CEBs, grande parte dos integrantes buscaram outras vias de participação sociopolítica, desvinculando dos núcleos iniciais.

Ainda que esta experiência proporcionasse participação ativa dos fiéis nos assuntos do cotidiano citadino, os setores tradicionais da Igreja Católica não simpatizavam com tais práticas (Mitidiero Junior, 2008). As CEBs foram pouco a pouco desestimuladas; consequentemente, as divergências nas ideologias político e econômica influíram para o enfraquecimento da atuação popular.

Ao tempo em que a Teologia da Libertação enfraquecia nas periferias das cidades, outro movimento religioso ganhava gradativamente espaço, a Teologia da Prosperidade. O discurso destas duas vertentes teológicas é oposto, embora sob a mesma origem, o cristianismo.

[...] se há um nome Teologia da Prosperidade, deve ter surgido em continuidade, ou em reestruturação, ou ainda em oposição a alguma outra teologia. Está-se referindo à denominada Teologia da Libertação: uma teologia que revive a Reforma Protestante, indo, por um lado, contra agora a Igreja Católica e seu sistema colonial e, por outro, contra as Igrejas Protestantes aliadas ao capitalismo industrial e ao imperialismo. Em meio ao sofrimento que essa situação gera, estão os escravizados os pobres (Silveira, 2007: 22).

A análise weberiana sobre o discurso protestante consiste em justificar a acumulação das riquezas como indício da salvação do indivíduo, e que cada um é instrumento da vontade de Deus para influenciar e transformar o mundo. As denominações de matriz histórica, tais como presbiteriana, luterana, metodista e batista, apesar de interpretar o texto bíblico crendo nas bênçãos e dádivas divinas, possuem pontos divergentes comparados aos pentecostais e neopentecostais. Os pentecostais e neopentecostais se distinguem também por possuírem práticas, costumes e algumas liturgias diferentes; os pentecostais ainda conservam a ideia de comunidade, cujos membros são conhecidos e filiados à denominação, enquanto que os neopentecostais, apesar de conservar esta mesma prática entre os seus líderes, entre os membros não há rigidez quanto à filiação. A Teologia da Prosperidade é mais nítida entre os grupos neopentecostais e tende ao 


\section{SÃO PAULO15 17 LISBOA $25 \sim 26$ JUN 2020

afastamento da prática política popular e do engajamento na transformação social, uma vez que toda prosperidade é resultado do esforço individual e não estão atreladas às políticas públicas as melhorias na vida individual. Segundo Silveira (2007), o neopentencostalismo é mais expressivo entre pobres, menos escolarizados e moradores de áreas periféricas.

Esta é muito presente na dinâmica de novas igrejas cristãs. Para seus divulgadores, está na hora de parar de falar sobre justiça social, sobre direitos humanos e sobre as abominações da riqueza mal adquirida. Deus protege o fiel seguidor da lei, aquele que paga o dízimo, é submisso às regulamentações dos líderes e acata humildemente certas prescrições de antemão escolhidas (Silveira, 2007: 22).

A Teologia da Prosperidade tem sua origem nos Estados Unidos ao final do século XIX, num cenário de adaptação do discurso religioso à intensificação e crescimento de centros urbanos, à consequente mudança no padrão de vida, à transformação da cultura do entretenimento em negócios e aos avanços na ciência, tecnologia e indústria. Este novo dinamismo também afetou os padrões de atuação religiosa. O conflito dos interesses do indivíduo e interesses sociais se tornaram mais latentes ao final do século XIX. Anos mais tarde, a Teologia da Prosperidade se adaptou ao Brasil, sob novos paradigmas, tomando forma mais vigorosa ao final dos anos 1970 .

A interpretação neopentecostal consiste em compreender que cada indivíduo deve prosperar, apresentando ainda uma compreensão política conservadora, estimulada pelo sucesso fundamentado pelas práticas empresariais. Na verdade, este é um grupo extremamente heterogêneo, que tem sido "disputado" por diversas correntes políticas, uma vez que parte desse grupo exerce influência direta sobre seus fiéis, através dos meios de comunicação abrangentes em todo território nacional. Não se trata de um efeito isolado, restrito a um centro urbano ou região do país, mas se verificam fatores gerais nos diversos espaços urbanos. É possível inferir que a conduta religiosa reverbera na ação da população na cidade, definindo valores do trabalho, da política e das relações sociais.

As práticas políticas por meio da participação popular entre os neopentecostais são desestimuladas e as ações em torno da justiça e equidade social são praticamente inexistentes, prima-se pelo apoio a um "escolhido" para o exercício da função política; como Dardot e Laval (2016) mencionam quanto a interpretação neoliberal, uma compreensão que se aproxima da Teologia da Prosperidade, o sujeito não é compreendido como resultado dos planos de governo, ele se torna empreendedor de si, é responsável pela própria empregabilidade e, consequentemente, a marginalização e o desemprego são atribuídos como culpa, ou fracasso, desse mesmo sujeito. A pobreza é justificada não pela ausência das políticas públicas, mas pela falta de fé ou distanciamento dos princípios cristãos. Sob este aspecto há uma constante necessidade de ser incluído nos ciclos do consumo e não há uma reivindicação voltada para o poder público.

Os grupos neopentecostais tendem ao afastamento da compreensão de transformação coletiva; cada grupo busca eleger seus representantes políticos, que não propõem ações e medidas de alcance geral, mas ao atendimento clientelista dos seus congregados.

\subsection{Considerações finais}

A cidade se instala nos lugares pela presença maciça de uma humanidade misturada, vinda de todos os quadrantes e trazendo consigo interpretações variadas e múltiplas, que ao mesmo tempo se chocam e colaboram na produção renovada do entendimento e da crítica da existência. Na transformação e redução da 


\section{SÃO PAULO15 17 LISBOA $25 \sim 26$ JUN 2020

desigualdade social, o convite feito por Dardot e Laval (2016) é a proposição de contracondutas, buscando meios de estabelecer um embate aos procedimentos postos pela estrutura de mercado. Desse modo, uma contraconduta seria pensar nos direitos e garantias para usufruto da cidade e seus espaços, sem escalonar os usuários em função da renda e, principalmente, buscar o envolvimento dos cidadãos, ainda que o discurso religioso divirja.

Os adeptos da Teologia da Libertação e da Teologia da Prosperidade se encontram, inicialmente, sob o mesmo perfil: a população pobre, periférica e marginalizada. A insatisfação e a tentativa de mudança fizeram com que esses discursos fossem aderidos com maior rapidez. Não há, nesta análise, a intenção de justificar que uma prática religiosa seja melhor ou pior, mas o que se propõe a discutir são as características gerais desses grupos e como isso interfere na conduta individual, principalmente quanto à participação na política local, seja através de reivindicações, seja através de sugestões.

Existe uma confluência de elementos constelados; não há um determinismo das relações, mas uma convergência, um emaranhado de descontinuidades sobrepostas. Essa transição de interpretação das práticas religiosas implica em mudanças na condição e no modo de viver do indivíduo em sociedade. As categorias de influência da conduta religiosa têm se expandido, passando a ter uma idealização do bom cidadão ao bom religioso, que não questiona as injustiças sociais, porque "é assim, pois Deus o quis", incorrendo no deslocamento da responsabilização dos conflitos urbanos e das questões estruturais da esfera governamental para a esfera individual/espiritual. As transformações e melhorias também não são atreladas às políticas públicas; o sucesso individual é compreendido como esforço empreendido pela boa conduta e bom trabalho. Utilizando-se da confluência de elementos na composição constelar, é possível compreender que este cenário tornou-se propício para a ascensão de movimentos de direita no Brasil. Ademais, outras questões emergem neste mesmo ambiente: os efeitos tardios da crise econômica mundial; a construção de um mal comum à sociedade (relativas a destruição da moral e da família); fortalecimento do discurso da insegurança urbana, possibilitando o enrijecimento de normas, do exacerbado uso da violência e do uso de armas; além do total descrédito da antiga política e a necessidade de candidatos não atrelados a cargos públicos, ou políticos de carreira.

\subsection{BIBLIOGRAFIA}

ARRETCHE, M. (2015) Trazendo o conceito de cidadania de volta: a propósito das desigualdades territoriais. In: ARRETCHE, M. Trajetórias das desigualdades: como o Brasil mudou nos últimos cinquenta anos. São Paulo: Editora UNESP.

BOBBIO, N. (2004) A era dos direitos. Rio de Janeiro: Elsevier. Disponível em: https://edisciplinas.usp.br/pluginfile.php/297730/mod_resource/content/0/norberto-bobbio-a-era-dosdireitos.pdf. Acesso em fevereiro de 2020.

BRASIL. (1988) Constituição da República Federativa do Brasil Diário Oficial da República Federativa do Brasil. Brasília, DF, 05 de outubro de 1988. Disponível em: http://www.planalto.gov.br/ccivil_03/constituicao/constituicao.htm Acesso em fevereiro de 2020.

CACCIARI, M. (2010) A Cidade. Barcelona: Editorial Gustavo Gili.

CANOTILHO, J.J.G. (2003) Direito Constitucional e Teoria da Constituição, $7^{a}$ edição, Portugal: Almedina. 


\section{SÃOPAULO15 $17 \cdot$ LISBOA $25 \sim 26$ JUN 2020}

CARNEIRO, C. (2019) Cultura de Compliance e Cultura de Paz. GALILEU - Revista de Economia e Direito. v. 20, n. 1, p. 37-58. Disponível em: http://repositorio.ual.pt/handle/11144/4290. Acesso em fevereiro de 2020.

CARRIÓN, F. (1991) La investigación urbana América Latina. Una aproximación. In: Nueva Sociedad (114), 113-123. Buenos Aires. Disponível em: https://nuso.org/articulo/la-investigacion-urbana-en-america-latina-unaaproximacion/ Acesso em fevereiro de 2020.

CHARTIER, R. (2002) A história cultural - entre práticas e representações. Rio de Janeiro: DIFEL.

DARDOT, P.; LAVAL, C. (2016) A Nova Razão do Mundo - Ensaio sobre a Sociedade Neoliberal. São Paulo: Editora Boitempo.

LEFEBVRE, H. (2001) O direito à cidade. São Paulo: Centauro.

LENZA, P. (2013) Direito Constitucional Esquematizado, 17ª edição, São Paulo: Saraiva, 2013.

MITIDIERO JUNIOR, M. A. (2008) A ação territorial de uma igreja radical: teologia da libertação, luta pela terra e atuação da comissão pastoral da terra no Estado da Paraíba. Tese (Doutorado) - Programa de Pós Graduação em Geografia Humana - Faculdade de Filosofia, Letras e Ciências Humanas da Universidade de São Paulo.

RIBEIRO, L.C.Q.; CARDOSO, A.L. et. al.(2012) Reforma Urbana e gestão democrática: promessas e desafios do Estatuto da Cidade. Rio de Janeiro: Revan.

SILVA, J.A. da (2005) Curso de Direito Constitucional Positivo. São Paulo: Malheiros.

SILVEIRA, M (2007). O discurso da Teologia da Prosperidade em Igrejas Evangélicas Pentecostais. Estudo da retórica e da argumentação no culto religioso. Tese (Doutorado) - Programa de Pós-Graduação em Filosofia e Língua Portuguesa, do Departamento de Letras Clássicas e Vernáculas - Faculdade de Filosofia, Letras e Ciências Humanas da Universidade de São Paulo.

TELLES, V. (1993) Pobreza e cidadania: dilema do Brasil contemporâneo. Cadernos CRH, n.19. 